\title{
Trauma Narratives in Hiroshima Mon Amour
}

\author{
Wenxi Guo* \\ 1New York University,NY 10003, the United States of America
}

Abstract:This paper is based on the film Hiroshima Mon Amour,analyzing it through Vickroy's trauma narratives.It aims to give an analysis of its plot,characterization, and narrative discourse in relation to the fragmentation, dissociation of the character's identity, the capacity to produce symbols, and the composition of trauma incarnate.

Keywords:Film analysis; Hiroshima Mon Amour; Trauma narratives; Narrative Discourse

\section{INTRODUCTION}

Hiroshima Mon Amour is a French Left Bank romantic drama film directed by Alain Resnais,and released in 1959.It documented a story between a French-Japanese couple about post-war trauma and memory,being an epitome of the nonlinear storyline.It adopted a modernistic filmic technique that intersperses different time and space with newsreel footage and fictional storyline.Through a symbolic romantic story,it reflects the traumatic experience and the fear of forgetfulness of war.

The trauma narratives will manifest itself in perspectives of fragmentation, dissociation of the characters'identities, the ability to produce symbols,static images and motifs related with trauma, the composition of trauma incarnate,and dialogical conceptions of witnessing in relation to Laurie Vickroy's theory in Trauma and Survival in Contemporary Fiction. With Tom Gunning's theory of narrative discourse and Michel Chion's theory of sound,I will analyze the sequences through these aspects to discuss their cultural,and social reasons and effects.

\section{METHODOLOGY}

The overall methodology will be Laurie Vickroy's theory about trauma narratives, with the analytical approaches of Gunning's narrative discourse, and Chion's sound to further discuss certain elements in relation to the trauma theory.I will further explain these three theories and their relations in this section.

Initially,from Gunning's theory,it is possible for us to distinguish different narrative discourse levels derived from Genette's categories:the pro-filmic,the enframed image,and the process of editing ${ }^{[1]}$.Furthermore,Chion's theory of sound functions as"added value"in audiovisual illusion to display an expressive and informative value to create the definite impression,and accentuates the meaning in reality,bridge the relation between visual images and something one hears. The narrative discourse,as a basic technical tool of sequences/film analysis,will combine with the functions of sound to give a general and specific analysis of filmic elements that will contribute to trauma theories, and further facilitate the analysis of post-war female trauma and presentation of trauma in relation with moving images.

Vickroy's theory of trauma narratives demonstrates different sections and presentations of trauma.First,the narratives of"fragmentation"indicate that something"creates or maintains a profound disturbing sense of self,"and the attempt to resist it becomes a common strategy of the protagonists of trauma fiction" ${ }^{[2]}$.Both she and he share the fragmentation in the trauma theory.

Copyright (C) 2020 Wenxi Guo

doi: 10.18282/1-e.v9i4.1698

This is an open-access article distributed under the terms of the Creative Commons Attribution Non-Commercial License (http://creativecommons.org/licenses/by-nc/4.0/), which permits unrestricted non-commercial use, distribution, and reproduction in any medium, provided the original work is properly cited.

\section{Composing}

The postproduction of 3D animation is to compose the animation clips, sound and other materials made according to the script planned previously, with editing using non-linear editing software. Therefore, the animation could be composed as one.

The production of animated scene is not only a category in art design, but also a fusion of digital media technology and a product of the combination of technology and art. With the aid of computer technology, it is possible to break through the limitations of time and space and maximize the performance of animation.

\section{Reference}

[1] Lin Zhe. Analysis of 3D animation rendering technology [J]. Modern Film Technology, 2014 (09): 22-25.

[2] Bian Dan. Exploration based on the application of the renderer Mental Ray [J]. Computer Knowledge and Technology, 2017,13

(09): 207-208. 
Second,the sense of dissociation of the characters in novels or films explores the changing emotion and detachment on the spiritual aspect for them to imply their traumatic experience.The change of subjects or narrators in Hiroshima Mon Amour indicates that both protagonists are in a similar position,sharing the post-war trauma that has an indispensable impact on their routine of everyday lives.Moreover,the capability to produce metaphors implies that someone can create symbols in their inner world as a means of reposition,recapturing the original object,but are not equated with this object ${ }^{[3]}$.In the film,both characters have certain symbols/ motifs to imply their traumatic experiences and feelings.Besides, the victims who carry the traumatic memory themselves become the history of trauma or trauma incarnate as well.The collective trauma of the post-war victims and the personal trauma of her losing the beloved one function as the dialogical conceptions of witnessing in Hiroshima Mon Amour.

\section{ANALYSIS}

\subsection{Fragmentation}

Initially,her and his trauma relate to the loss of their closest beloved ones.For instance,she once witnessed the anti-war march passing by,which recalled her chaotic and traumatic memory at her early age when falling in love with a German soldier. Her trauma in Hiroshima Mon Amour,to some extent,touches the ordinary middle-class tragedy in France when she recalls her memory of her German fiancéwho lost his life in war.She kind of fragmented herself in the loss of lover and lui has imprisoned himself in the loss of his family members in bombing. The motif of war,scar,inner world,personal experience has intermingled together,triggering the emotion of two traumatic souls.In addition,this also triggers the pieces of memories she always deliberately attempted to forget,becoming more and more clear.They are clear enough to split her soul once more when she could not help pouring her heart out to him about her hidden past.For the first time in the film she recalls the trauma is that when she holds a cup of coffee,looking at him who is still asleep,lying on his stomach,fragmentary memories appear in her mind.This sequence applies to an appropriate technique of montage,cutting through the man peacefully lying down on the bed to a bleeding man lying on the ground, which indicates her frequent flashbacks to previous trauma when she sitting with him at the bar.The non-linear narrational mode accentuates the tense of the story,facilitates the characterization of her,and creates a reasonable connection to him and the German fiancédied in the war.It arouses the spectator's interest of who the dying man is, what relations among the three characters are,foreshadowing the continuous traumatic fragments in her mind that will appear in the next few scenes.Besides,a similar way of editing appears when she attempts to talk about her past to him on the bed.With her voice saying"at first we met in barns. Then among the ruins.And then in rooms,"her expression of recalling her memory functions as a general montage of images in her mind,in her voice,and in the sequence as well.From the editing and sound,it is obvious to see that though she begins to tell him about her traumatic history,she still remains something stocking and shadowing in her mind,for the reason that she somehow answers the questions that he once asked,but she does not speak out loud.The shots of scenic views in Nevers conceal her inner world from him and the spectators,indicating there will be a climax in relation to the previous memory in Nevers later.

\subsection{Dissociation}

Furthermore,the sequences that imply a sense of dissociation combine naturally with the storyline.In Vickroy's theory,the switch or the exchange of the positions of the subject creates emotional,spiritual detachment---the heroine's film work about peace,memory of loss, and his traumatic memory of the atomic bombing event.The film Hiroshima Mon Amour meets with her approval in several aspects:the selection of props,camera distance, and angle,framing for composition,editing, and sound.

At the first level of pro-filmic,lightings convey the narrative information through different pre-existing selections. The opening sequence and following sequences related to their bodies apply to low key and high-contrast lightings, which emphasizes the function of lightings as the"language of tone"[4].Since the low key suggests restraint,severity,somberness,and sometimes grief,the cinematography facilitates the spectator to convey the message of how to interpret the action and scene in this sequence.Through the cinematic device, the sense of sorrow,loneliness, and grief are displayed on the screen before the spectator seeing their faces.

Besides, at the second level of the enframed images,camera distance and angle construct the image as a powerful narrative cue to express the characters'moods.For instance,the opening sequence of the body in an embrace includes several cuts of shoulder gripping movement.It is possible to observe that the shots of embracing are from different angles, and from different distances. The first two shots frames view nearby the couple who embraces each other with their arms'movement,and then it cut to the back of him. Only the dark background, the back of man,and the woman's hands fondling,or griping his back can be seen in this shot.When cutting back to the same scene,the shot frames the close-up of his shoulder and her left hand.The exchange of camera distances is very intriguing.From the first shot,it is hardly for us to distinguish the man and woman from their bodies, since the ash has covered other features of their bodies.In the second shot,we can first distinguish them from the color of their skin:the male seems dark, while the female is light.In the next shot,we distinguish them through the masculinity of the male's back,and the femininity of the female's fingers.From a different distance,the camera exposes certain features of male and female for the spectator to distinguish rather than directly shows their faces. This technique,to some extent,shapes an illusion as if their positions of the subject are determined by the spectator,indicating that they are drifting with the current,and either of them can represent the other since both of them share a tragic and traumatic experience. Only sexual intimacy allows them to relieve the pressure, and the selections of camera distance and angle interpret the hidden loneliness, sorrow in their spiritual world.

Finally, at the third level of editing, it directly alters the position of subjects/narrators through crosscutting,non-linear narrational modes, the alternative tenses, and sequences or footage of different time and space.For the sound,meanwhile,different voices of narrators/characters convey different messages to the spectator.Combining with the moving images, the sound affects editing and the total pace of the storyline.Since when the first time when her voice-over saying"I saw everything in Hiroshima,"the shot cuts to the footage of hospital,where she sees"everything"-wounded people,nurses who deliberately gazing at the camera,and the 
patients who are obviously indifferent to the camera - that combines with the coldness of war,and collective traumatic memories. She sees everything that indicates the hidden personal and even psychic trauma under normal facial expressions,actions,and appearance.What's more,when he rejects her opinion that"you saw nothing,"the scene cuts to an empty museum,with hollow model structures,mutilated iron,wax models, and etc. The montage of still images of museums confirms that"nothing"is being seen here in Hiroshima,implying the situation after the atomic bombing that Hiroshima has become a city of hollowness, a city of loss,and a city of trauma.Their changing voice-over in this sequence affects editing,and indicates the subjectivity of the narrators since after one of their voices, the theme of editing turns out to be his or her specific point of view.Combined with editing,sound functions as the trigger to switch the positions of subject to emphasize the altered temporal and spatial relations,and accentuate the traumatic memory as well.

\subsection{CAPACITY TO CREATE METAPHERS AND MOTIFS}

Moreover,the symbols,metaphors, and motifs in the film imply the fear of traumatized individuals and traumatic memories. This phenomenon indicates the"speechless terror"that it is not possible for the traumatized individuals to directly utilize the language code to express their feelings or trauma.In this case,symbols or metaphors like"bread and wine"displace"body and blood"to create a less offensive condition for the traumatized persons, indicating their victim identity at the same time.For instance,in the first few minutes of the film,plenty of motifs appear and the spectator,to some extent,is bombarded by the symbols and metaphors. The opening sequence crosscuts bodies in an embrace,and as if ash,rain,sweat has soaked them,and then with nothing but naked bodies. The sequence of the couple firmly griping each other exists for a long time,without seeing the faces of them.As the images fading out,the spectator is brought to a hospital,walking along the hallway,observing everyone who directly looks at us,and the patient on the bed slightly glimpses to the camera and coldly turns back her head.Then,the sequence is edited back to the nude couple,fading out,and to Hiroshima in ruins.Cutting back and forth,repeatedly,creates the motif cycle of physical intimacy and post-war spiritual trauma.Besides, we can indeed see everything,but we can see nothing at the same time. We could not see the atomic"mushroom,"and the terrible ruins,since a brand-new Hiroshima in order has been restored. What we can observe is that the nuclear-contaminated animals,burnt human beings,bones,and the never-ending trauma that can be easily intensified left behind in their inner world.To further elaborate on the traumatic motifs and metaphors, the characters themselves in the film functions as trauma incarnate to"balance between the emotion recurrently breaking through the'protective shield'and numbness that protects this shield"[5].Through the motif of hollowness,replacement,and distortion,we figure out the material and spiritual world of an individual.The superimposed filmic narratives are more fascinating than the simple footage or linear documented events.

\subsection{TRAUMA INCARNATE}

In addition to the motifs and metaphors, the character of she and he function as trauma incarnate themselves in the film,expressing the traumatic memories,and indicating the collide of traumatic history in different ideological and physical experience.For Elle,she finally exposes her traumatic experience in Nevers, the wound of scraping and rubbing off the stone-made wall,bleeding in her hands, and her mind.She was imprisoned in her room,in the cellar,but virtually she was imprisoned in her memories.For instance,the sequence when she is kept in the cellar indicates that the camera movement,sound,and editing facilitate the composition of her inner world.The zooming-in of her when she screams and pats the closed and blinded window focus the spectator's attention on her action. With the voice-over of hers, we are cognizant of the content of her screaming-the name of the German soldier.However, this voice-over is in the dialogue with him who asked"what do you scream",while she answers with"your name,your German name,"intermingling the character of lui and the German soldier's identity together as if they share a similar quality to Elle - the archive of trauma.Then,she was imprisoned in the cellar. The panning movement of the camera explains that her family let her out when she stopped screaming.Accompanied with the editing,the voice-over dramatizes shots,orienting them toward a goal and creating a feeling of expectation,implying the added value in relation to the perception of time in the image ${ }^{[6]}$. The sound orients the shot to her lying on the bed and her eyes filled with unprecedented desire."I'm afraid,everywhere,"she said softly,indicating her fear of the room,the cellar,and everything in Nevers after the death of her German lover.Then,the montage of the ceiling of her room, and some meaningless items in Nevers implies that her fear to the memory of Nevers transplanted to specific physical materials,and to the town itself.She,therefore,combines with her spiritual trauma to physical materials as well as synchronizing the Japanese man with her lost lover.At this juncture,the bar in Hiroshima with wartime Nevers, the Japanese architect with the German soldier intermingles together,blurring the borders of past and present,here and elsewhere,material and mental world.The crosscutting shots,constant voice-over,changing scenes,and moving camera produce an effect of distortion,in which it is hard to tell the authentic emotion and the expectation to the characters. The sense of disconnection and isolation confuses the characters of where they are from and where their destination is. When the non-linear shots appear,again and again,the sense of nostalgia and forgetfulness spreads among the characters and leaves in the memory that once being concealed in her mind,reminding the spectator that she will leave Hiroshima the next day.

The characters represent the trauma of Nevers and Hiroshima respectively.In the bar,when she gradually talking about her own memory in the wartime Nevers, the figure lightings on her indicates that she pours out her heart as a traumatized victim in contrast to him,as a listener who witnesses her piecing the puzzle of the memory. This process fits Vickroy's theory that evokes the physical and durational qualities of witnesses'experiences,"incarnating"them through the trauma exposure(Vickroy, 175). She becomes the trauma of Nevers herself to unveil her stories to the trauma of Hiroshima,him,and the process of"incarnating"is painful.Scholar Laub and Auerhahn suggest,recalling the history of trauma, which break through the burdens of dissociation,dislocation,repressio $\mathrm{n}$, and isolation, has been depicted as"being caught between the compulsion to complete the process of knowing and the inability or fear of doing so" ${ }^{[7]}$.Both of the post-war traumas incarnate physically and spiritually collide to break the"shield"of fear and to move forward as if her hair that once shortened gradually growing back. 


\title{
The path of incorruptible culture into Ideological and political education in Colleges and Universities
}

\author{
Yuxue $\mathbf{L v}^{*}$ \\ Qingdao University shandong qingdao 266000, China.
}

Abstract:Traditional culture of clean government has rich connotation,including political ethics, life style, way of life,self-cultivation and other aspects,including benevolent government and loving the people,honest and impartial,impartial law enforcement,lawabiding,thrifty and other ethical norms. The traditional culture of clean government and the idea of Ideological and political education in Colleges and universities are internally consistent and mutually integrated.The combination of the two has profound value implication, which can set a good example of integrity,guide integrity cultivation and optimize personnel training.

Keywords: clean government culture;ideological education; traditional culture

From the structural system of integrity of clean government culture,to integrate the traditional clean government culture into the ideological and political education in Colleges and universities,it can be divided into two different parts:one is the external part of clean government organization,clean government environment,clean government system, and the other is the internal abstract part of clean government thought,clean government consciousness,clean government psychology. We can promote the integration of traditional anti-corruption culture into the ideological and political education in Colleges and universities from the aspects of curriculum integration, organization integration,management integration, and culture integration.

\section{Classroom integration:promoting the classroom teaching effect of traditional clean government culture}

On the one hand,we should give full play to the dual subjectivity of teachers and students. The classroom is not a teacher's speech,but a place of knowledge dissemination formed by the interaction between teachers and students. The traditional education mode overemphasizes the subjectivity of teachers and emphasizes the cramming education. Teachers have the absolute right to speak, and students should accept the teacher's instruction unconditionally and passively.The subjective status of both teachers and students is covered,which damages the effect of Ideological and political education in Colleges and universities. Therefore,we need to give full play to the subjective role of teachers, through teachers'accurate grasp and deep understanding of the traditional clean government culture,actively guide students to learn the knowledge of clean government,conduct in-depth thinking and

doi: $10.18282 / 1-$ e.v9i4.1699

This is an open-access article distributed under the terms of the Creative Commons Attribution Non-Commercial License (http://creativecommons.org/licenses/by-nc/4.0/), which permits unrestricted non-commercial use, distribution, and reproduction in any medium, provided the original work is properly cited.

\section{CONCLUSION}

Overall,according to the theories of Vickroy's, the trauma narrative manifests itself through aspects of fragmentation,the capacity to produce metaphors and motifs, and trauma incarnate. The fragmentation to confine herself in a disguise,the metaphors and motifs of trauma, and the collide of collective and personal memories have attributed to the analysis of trauma narratives in Hiroshima Mon Amour.The characters of"she"and"he"would also be interpreted as"you"and"me"to the spectators,revealing their trauma experience concerning the historical events or personal memories.In retrospect,past experience adds weight to the duration of time and arouse the question of forgetfulness. Though the analysis of narrative discourse and sound,the characters in the film are immersed in the inescapable prison of trauma.

\section{Reference}

[1]Gunning,T.(1999).“ Narrative Discourse and the Narrator System.” Leo Braudy and Marshall Cohen,eds.Film Theory and Criticism: Introductory Readings.5th ed.New York:Oxford University Press.[2]Vickroy,L.(2002).Trauma and Survival in Contemporary Fiction.United States:University of Virginia.

[3]Segal,H.(1981).“ Notes on Symbol Formation.” The Work of Hanna Segal:A Kleinian Approach to Clinical Practice.New York:Aronson. 49-65.

[4]Keating,P.(2010).Hollywood Lighting from the Silent Era to Film Noir.United States:Columbia University Press.

[5]Friedlander,S.(1992).“ Trauma,Transference,and“ Working Through’ in Writing the History of the Shoah” History and Memory.(4):3959.

[6]Chion,M.(1990).Audio-vision:Sound on Screen.New York:Columbia University Press.

[7]Laub,D,and Nanette C.A.(1993).“ Knowing and Not Knowing Massive Psychic Trauma:Forms of Traumatic Memory.” International Journal of Psychoanalysis (74.3):287-302. 